\title{
APRESENTAÇÃO: GEORG SIMMEL E AS FORMAS DE VIDA
}

\author{
Arthur Bueno' \\ Eder Malta ${ }^{2}$ \\ Elaine da Silveira Leite ${ }^{3}$
}

É notável, nos últimos anos, o crescimento da produção acadêmica a respeito da obra do filósofo e sociólogo alemão Georg Simmel (1858-1918), indice de um interesse renovado não apenas por sua sociologia e seu diagnóstico da modernidade, mas também por sua epistemologia, sua estética e sua metafísica da vida. Tendo em vista a aproximação dos cem anos de seu falecimento, este dossiê tematiza os escritos simmelianos com o propósito de destacar sua relevância para as ciências sociais e a filosofia contemporâneas. Autor de uma obra reconhecidamente variada, Simmel é com frequência encarado como um ensaísta cujos argumentos não se deixariam sistematizar de uma perspectiva unificada. A despeito disso, uma linha de continuidade percorre os seus textos: trata-se daquela que, formulada de diferentes maneiras ao longo de sua obra, traduziu-se finalmente em uma contraposição entre vida e forma. Tal como articulada por Simmel em seus últimos escritos, a relação entre esses polos não se caracteriza somente por um conflito insolúvel, mas também por uma inescapável dependência: ao passo que a vida só pode emergir cristalizando-se em uma forma determinada, que a particulariza e delimita, forma alguma é capaz de se sustentar sem a referência ao fluxo vital que é acolhido e transformado em seu interior. A obra de Simmel pode, assim, ser compreendida como uma extensa e variada investigação das formas de vida - e é com isso em vista que este dossiê apresenta um conjunto de trabalhos explorando as diferentes figurações desse tema nos textos do autor.

\footnotetext{
1 Centro Max Weber de Estudos Culturais e Sociais Avançados da Universidade de Erfurt, Alemanha. Contato: arthur.bueno@uni-erfurt.de

2 Programa de Pós-Graduação em Sociologia da Universidade Federal de Pelotas. Contato: ecmsouza@gmail.com

3 Programa de Pós-Graduação em Sociologia da Universidade Federal de Pelotas. Contato: elaineleite10@gmail.com
} 
No artigo "Georg Simmel e o problema da desigualdade social”, Berthold Oelze aborda a posição do autor acerca das origens e da dinâmica dos conflitos sociais e das revoluções. Como ponto de partida, é apresentado ao leitor um escrito menos conhecido de Simmel, intitulado "Rosas. Uma hipótese social", construído na forma de conto de fadas e publicado anonimamente em 1897 na revista alemã Jugend. Referindo-se de maneira cifrada às revoluções e lutas politicas na Europa dos séculos XVIII e XIX, essa ficção representa uma das raras ocasiões em que Simmel expôs mais claramente suas convicções políticas a respeito do problema da desigualdade e da chamada "questão social". Oelze estabelece uma linha de continuidade entre o conto de fadas simmeliano e as utopias filosóficas e literárias que marcaram tal período histórico, nas quais se incluíam, à sua maneira, as propostas do marxismo. Nas respostas oferecidas por Marx e Simmel à pergunta sobre a origem da desigualdade social se destacam, contudo, as diferenças entre tais autores: enquanto Marx situa o problema na estrutura da sociedade de classes e na propriedade privada dos meios de produção, Simmel oferece sobretudo uma explicação de tipo psicológico. A fina sensibilidade humana para as diferenças, na qual se apoiam os sentimentos de privação ou de orgulho, de inveja ou de arrogância, explicaria por que mesmo revoluções bem-sucedidas na realização de seus anseios igualitários são seguidas de novas insatisfações e, logo, novas lutas (cada vez mais específicas) por justiça social.

A ênfase simmeliana nos processos psicológicos é também retomada, ainda que em outra vertente, no artigo "Simmel e a confiança", de Rodrigo Mota. Se o texto anterior aborda o problema das origens da desigualdade, aqui o foco é a possibilidade mesma da vida social em um contexto crescentemente diferenciado. Articulando as diversas referências de Simmel à confiança (ou à desconfiança) em seus escritos sobre o dinheiro, a metrópole, a religião e o segredo, Mota fornece um panorama dos usos dessa categoria na obra do autor. A importância que Simmel atribui ao tema é observada, por exemplo, na forma assumida na modernidade pela economia do crédito (Kreditwirtschaft), cujo significado ultrapassa o âmbito econômico: ela envolve sobretudo a crença ou a lealdade dos indivíduos uns em relação aos outros, estabelecendo assim as condições para a unidade social. Por sua vez, se para 
Simmel a confiança aparece em sua forma mais pura na fé religiosa, na impessoalidade das grandes cidades prepondera antes a desconfiança. Como quer que seja, a confiança é um elemento indispensável à interação social, na medida em que envolve um conhecimento mútuo entre indivíduos que, embora nunca se torne absoluto, implica sempre algum acesso à subjetividade do outro. Ela não se restringe, porém, ao nível interpessoal, como demonstra o caso das sociedades secretas, que resguardam suas práticas rituais e mantêm desse modo sua existência por meio da confiança entre seus membros. Por fim, diante das incertezas e da falta de conhecimento completo sobre o outro, Mota destaca a importância da suspensão, o ato de fé no próximo que representa um aspecto crucial, porém contingente, da confiança e põe em questão as formas reflexivas da racionalidade como principal fundamento da vida em sociedade.

Sobre o pano de fundo da crítica à racionalidade e da busca por novas formas de conhecimento que floresceram na Europa naquele período, Gustavo Martins C. Miranda discute as origens e os destinos do pensamento social vitalista elaborado por Simmel no início do século XX. O artigo "Simmel e os caminhos para o desenvolvimento de uma sociologia vitalista" apresenta, de um lado, as ideias centrais de autores do século XIX associados a essa linha de pensamento, e, de outro, a maneira pela qual elas foram continuadas e transformadas na obra simmeliana. Nos escritos vitalistas, a cultura da modernidade é compreendida a partir de narrativas voltadas sobretudo para a experiência pessoal. Daí, como afirma Miranda, o vínculo entre as categorias de cultura e de vida. Em termos filosóficos, tal corrente é marcada pelo distanciamento em relação à influência kantiana e seu arcabouço racionalista, uma contraposição que é igualmente central para os desenvolvimentos sociológicos do pensamento vitalista: segundo Miranda, suas premissas epistemológicas dão ênfase à unidade da vida subjetiva (indivíduo) em detrimento do primado do objeto (sociedade). Em linha com essa perspectiva, Simmel concebeu as dinâmicas sociais concedendo atenção particular à construção dos conteúdos vitais e à redefinição das formas pelos indivíduos. Seus argumentos se tornaram, desse modo, cruciais para diversos autores atuais que discutem a possibilidade de uma sociologia vitalista. 
Em “Georg Simmel e a crítica à objetividade do conhecimento", Murilo Canella discute as posições do filósofo e sociólogo alemão a respeito da natureza do conhecimento objetivo sobre a realidade social. Confrontando o racionalismo estreito da ciência e o anseio em captar a totalidade da vida mediante o desenvolvimento de conceitos e categorias lógicas, tal crítica, segundo o autor, fornece uma via de acesso privilegiada ao "universo heurístico, gnosiológico e metodológico de Simmel”. Canella desenvolve, assim, os vínculos entre a crítica simmeliana à objetividade e dois temas centrais de sua obra: a cultura e o individualismo modernos. As censuras ao racionalismo estreito não implicam, contudo, uma rejeição da objetividade do conhecimento; antes, elas procuram expor a artificialidade dos conceitos perante as dinâmicas interligadas da individualidade e dos conflitos que configuram a tragédia da cultura. Um eixo central dessa perspectiva consiste, assim, na consideração dos hiatos entre a vivência imediata e a conceitualidade formal, manifestados não apenas no âmbito das questões epistemológicas, mas também nos descompassos entre as dinâmicas vitais e as formas culturais. Na esteira de Donald Levine, Canella defende o "crítico Simmel” em relação àqueles que o consideram um esteta e um teórico inconsistente, concluindo que "a crítica à objetividade do conhecimento não o desqualifica (Simmel não concebe a modernidade sem os constructos da ciência e suas ambivalentes potencialidades); antes, o situa em uma arena reflexiva concernente a suas limitações fundantes".

A relação entre a vida e as formas não é, todavia, somente um problema epistemológico, ela é também uma questão estética. No artigo "Como a arte (contemporânea) se apresenta? Sobre a atualidade de 'A moldura' de Georg Simmel”, Glaucia Villas Bôas retoma o ensaio simmeliano sobre o significado do enquadramento para a obra de arte, publicado em 1902 no jornal berlinense Der Tag, com o propósito de discutir sua pertinência para a arte contemporânea. Como destaca Villas Bôas, Simmel concebe a moldura como elemento central para a visualização contemplativa de uma obra, reforçando a autonomia desta última na medida em que simboliza sua unidade e suas fronteiras em relação ao que é exterior. Porém, no bojo das transformações no campo artístico intensificadas a partir da década de 1960, uma nova política 
da arte emergiu em sentido contrário à autonomia da obra e à submissão do espectador ao objeto estético. Considerados à luz dessa proposta de aproximação entre a arte e a vida, os argumentos de Simmel podem parecer ultrapassados. No entanto, Villas Bôas mostra como algumas das categorias centrais do autor - todo e parte, heterodoxia e autonomia, distância e proximidade, enquadramento e ausência de limite - podem ser recuperadas para analisar sociologicamente a arte contemporânea. Em sua defesa da atualidade do ensaio simmeliano sobre a moldura, a autora põe à prova os argumentos do autor por meio da análise da exposição Acervo em Transformação, de considerações sobre a apropriação da fotografia como fazer artístico que evidencia a quebra ou mesmo o "fim" da moldura e, finalmente, de uma reavaliação do projeto de reunir a arte e a vida a partir das reflexões do próprio Simmel sobre a modernidade.

Igualmente dedicado às formas de vida artísticas, o artigo "La promesa del arte. El artista como educador de identidades colectivas", de Amalia Barboza, encontra nos ensaios de Simmel uma caracterização da arte não somente como meio de expressão de emoções individuais, mas também como instrumento de canalização de identidades coletivas. Debruçando-se sobre a função social da arte e as relações entre artista e público, a autora defende que a arte cumpre a promessa de construir pontes de entendimento entre os individuos e as diferentes expressões culturais. A partir dos escritos de Simmel sobre Rembrandt e Rodin, bem como de canções de Caetano Veloso e Chico Buarque, o artigo destaca a capacidade da arte em criar um campo de atração estético e emocional, de modo que o significado imanente à obra estabelece, em seu raio de ação, laços de compreensão entre uma diversidade de pessoas. Tal promessa da arte, no entanto, só dura até o "aplauso final": "En el momento en que la expresión artística concluye, vuelven las diferencias y la identificación grupal desaparece". Assim, "El arte se presta [...] a diferentes identidades colectivas y los artistas parecen tener la función, quieran o no, de servir de puentes hacia esas colectividades". A conclusão de Barboza é que, em seus escritos, Simmel busca na arte a superação de diferenças contingentes para unir as diferentes identidades ou, na expressão do próprio autor, para cruzar os diferentes círculos sociais. 
Já o artigo de Tálisson Melo de Souza, "Arte e cidade comprimidas: a exposição como símbolo da modernidade em Simmel", volta-se para as relações entre experiência estética e estilo de vida moderno, destacando em especial os ensaios do autor sobre as exposições de arte e a exposição industrial de Berlim. Ao passo que as primeiras são compreendidas a partir da especialização moderna da arte e, desse modo, como resultado de um processo de diferenciação em relação à monotonia e à uniformidade do mundo do trabalho, as exposições de produtos industriais são vistas em sua capacidade de proporcionar a fruição lúdica de uma imensidão de objetos dados à vista de maneira concentrada. Observando tais exposições, Simmel “enfatiza a ânsia por maior intensidade da produção de novos estímulos (excitações, interesses e gozos), que levem o indivíduo de estados de anestesia para a hiperestesia garantida em um curto período de tempo". Souza destaca, assim, que a perspectiva simmeliana fornece caminhos para a análise das afetações mútuas entre a vida mental e a sensibilidade estética e espaçotemporal dos indivíduos nos contextos de produção e recepção das realizações da cultura.

Encerrando este dossiê, o artigo "The conflict of social life and cultural forms. Simmel's theory of 'qualitative societal differentiation", de Gregor Fitzi, fornece uma interpretação abrangente da teoria simmeliana da diferenciação social, considerando as formulações do autor em momentos distintos de seu percurso intelectual. Para Simmel, o aumento da diferenciação social e a multiplicação de funções nas sociedades modernas intensificam a interdependência entre os indivíduos, ao mesmo tempo em que os vínculos pessoais que lhes são impostos se tornam menos rígidos, permitindo uma maior margem de liberdade individual e a participação em diferentes círculos sociais. Nesse sentido, "social differentiation has to be assessed as a parallel process, which is ongoing within the social group and the individual personality, because social agency is considered to be a structure and a building block of complex societies" - e nisso reside a principal diferença entre a teoria simmeliana e a de Émile Durkheim. Além disso, segundo Fitzi, a realidade social é conformada como o domínio da experiência de vida inerente à interação social e à consciência dos atores sociais. Assim, cada domínio da 
sociedade se desenvolve de acordo com uma lógica própria que gradualmente autonomiza em relação às outras, desencadeando uma "diferenciação qualitativa da sociedade". Por fim, o artigo mostra como a antropologia sociológica tardia de Simmel se vincula às suas formulações anteriores sobre a diferenciação social, as dinâmicas da cultura e as premissas epistemológicas da sociação em uma teoria das formas de vida no contexto de "sociedades qualitativamente diferenciadas".

Uma ótima leitura! 